\title{
Sonographic determination of spleen to left kidney ratio among Igbo school age children of south east Nigeria.
}

\author{
Eze CU ${ }^{1}$, Agwu $\mathrm{KK}^{1}$, Ezeasor $\mathrm{DN}^{2}$, Agwuna $\mathrm{KK}^{3}$, Aronu $\mathrm{AE}^{4}$
}

1. Department of Medical Radiography and Radiological Sciences, Faculty of Health Sciences and Technology, Univ ersity of Nigeria, Enugu Campus, Enugu State, Nigeria.

2. Department of Veterinary Anatomy, Faculty of Veterinary Medicine, University of Nigeria, Nsukka Campus, Enugu State, Nigeria.

3. Department of Radiation Medicine, Faculty of Medicine, University of Nigeria Teaching Hospital, Ituk-Ozalla, Enu gu State, Nigeria.

4. Department of Paediatrics, Faculty of Medicine, University of Nigeria Teaching Hospital, Ituk- Ozalla, Enugu State, Nigeria.

\begin{abstract}
Background: Clinical determination of mild splenomegaly is notoriously inaccurate. among school age children in a tropical environment. weight street clothes without shoes. absence of renal disease among school age children.

Keywords: Ultrasound; measurements; spleen size; school age children.

African Health Sciences 2014;14(1): 246-254 http://dx.doi.org/10.4314/ahs.v14i1.38
\end{abstract}

Objectives: To determine sonographically the spleen to left kidney ratio according to age and somatometric parameters

Methods: A cross sectional study and convenience sampling were done on 947 apparently healthy subjects (496 boys and 451 girls) aged 6 - 17 years at the University of Nigeria Medical Centre, Nsukka. The sonographic examination was performed on Shenzhen DP-1100 machine with 3.5 and $5 \mathrm{MHz}$ convex transducers. Spleen and left kidney lengths were obtained using appropriate techniques. The weight and height of the subjects were obtained with the participants wearing light

Results: Measurement of spleen and left kidney lengths were reliable within and between sonographers. The spleen and left kidney lengths were not statistically different in boys and girls ( $p>0.05)$. The spleen to left kidney ratio according to age and somatometric parameters is constant at about 1.13 with 1.3 as the upper limit of normal in the studied population.

Conclusion: Sonography can be used to detect mild splenomegaly if the spleen to left kidney ratio is greater than 1.3 in the

\section{Introduction}

Malaria, tuberculosis, typhoid fever and other water borne parasitic infections are a major public health concern in Nigeria. In 2003, it was estimated that half of the Nigerian population has at least one episode of malaria annually, and majority of outpatient visits can be attributed to malaria. ${ }^{1}$ This is similar to exposureto tuberculosis and water borne parasitic infections.

The spleen is a reticuloendothelial organ involved in

\section{Corresponding Author: \\ Eze Charles Ugwoke \\ Department of Medical Radiography and \\ Radiological Sciences, Faculty of Health \\ Sciences and Technology \\ University of Nigeria Enugu Campus, \\ Enugu State, Nigeria. \\ E-mail: ugwoke.eze@unn.edu.ng \\ ezecharlesu@yahoo.com}

defense against infection and infestation and thus it is expected that the spleen may be slightly comparatively larger in exposed subjects than to what is obtained in non exposed subjects.

The morphological characterization of the spleen is one of the many parameters that assist in detecting splenic disorders and systemic infections, inflammatory and malignant pathologies. Invariably the complete characterization of the disease process may need morphological assessment of anatomical structures and laboratory reports. However, there are many conditions where organomegaly may be the only feature on ultrasonography like splenomegaly in malaria. On the contrary, clinically palpable spleen may not be pathological. Pushed down spleen due to subdiaphragmatic pathology, visceroptosis and palpable spleen in $10 \%$ to $15 \%$ of normal children are a few examples of palpable spleen without any clinical significance ${ }^{2}$. Clinical assessment of changes in visceral organ size is difficult and unreliable ${ }^{3}$. Ultrasonography is a non-invasive, established, safe, quick 
and accurate method for measurement of spleen and kidney sizes ${ }^{4}$.

It is important to compare the length of the spleen to the length of the left kidney in order to establish an internal reference standard against which the spleen size can be calibrated. Loftus and Metreweli ${ }^{5}$ as well as $\mathrm{Al}$ Imam et $\mathrm{al}^{6}$ found that the spleen to left kidney ratio among children was constant for all age groups with a mean value of 1 and proposed a ratio of 1.25 as the upper limit of normal. In a similar study in adult population, spleen length was correlated with left kidney length in women, but not in men and they found the spleen to left kidney ratio to be an unreliable index for spleen size in adults ${ }^{7}$. Racial differences in the normal length and width of the spleen have been shown to exist ${ }^{8}$. There is paucity of data in the tropics on the spleen to left kidney ratio with reference to age and somatometric parameters among school age children which will serve as an internal reference standard against which the spleen size can be calibrated. This research could be related and introduced into a more diverse population by ensuring population specific charts to compensate for demographic variations in spleen dimensions.

The aim of determining the spleen to left kidney ratio in the present study was to provide a more objective assessment of mild splenomegaly during routine abdominal ultrasound in our school age children population without reference to a normogram as clinical examination is notoriously inaccurate.

\section{Subjects and Methods}

The study was carried out using a cross sectional research design and convenience sampling method at University of Nigeria Nsukka Medical Centre between January 2010 and May 2011.

Sample Group: These include Igbo school age children aged 6 to 17 years. The age of each subject was obtained from his/her hospital birth certificate. Some of the children attended hospital for clinical reasons while majority of them attended hospital just as volunteers for the study.

Selection Criteria: Volunteers and outpatients were examined by a pediatrician and those who met the following selection criteria were enlisted in the study.

Exclusion Criteria: Subjects with tropical splenomegaly syndrome (malaria and typhoid fever), lymphaden- opathy, sickle cell disease, obesity, splenic parenchymal mass lesions, accessory spleen and cysts were excluded from the study. Also subjects with acute or chronic renal failure, renal parenchymal mass lesion, cysts, hydronephrosis or calyectasis were excluded because of possible enlargement or reduction of these organs.

Inclusion Criteria: Subjects with no history of malaria, typhoid fever, malnutrition, sickle cell disease or obesity and subjects with no evidence of splenic parenchymal mass lesions, abnormal echotexture of the spleen, accessory spleen and cysts were included as normal subjects. Also apparently healthy subjects and subjects with normal sonographic appearances of the kidneys were included in the study.

Ethical Approval / Informed Consent: Ethical approval was obtained from the Ethics Committee of the University of Nigeria Nsukka Medical Centre. In addition informed consent was obtained from each participant's parent before data collection began. A chaperon was available during data collection on female subjects.

Equipment: The sonographic examinations were performed with high resolution real time scanner (DP1100, Shenzhen Mindray Biomedical Electronics Co. Ltd, China) manufactured in 2008 with $3.5 \mathrm{MHz}$ and 5 $\mathrm{MHz}$ convex transducers. Using the available freezeframe capability, all the sonographic measurements were made with curvilinear probes using the electronic calipers.

Demographic data were collected on each participant at the time of their pre-participation physical examination. This information included age, sex, height and body weight whereas BSA and BMI were computed from measured height and weight. Body mass index was calculated by BMI $=$ weight $(\mathrm{Kg}) /$ height $\left(\mathrm{m}^{2}\right)$ while BSA was calculated by BSA $=V_{\text {weight }} \mathrm{x}$ height $/ 3600^{9}$. Anthropometric measurements were obtained on the participants wearing light weight street clothes without shoes. Weight was measured on a calibrated portable Salter scale (BR 9011; Hana Co. Ltd, China) to the nearest $0.1 \mathrm{~kg}$. Height was measured with a metal tape measure to the nearest $0.5 \mathrm{~cm}$ with the participants standing upright with the head in the Frankfurt position ${ }^{10}$.

Scanning Technique: A coupling medium was first applied to the area being scanned to ensure good transmission of the ultrasound beam into the subjects. 
The technique of right lateral decubitus position in formed between the most superomedial and the most the coronal plane was adopted for the spleen length inferolateral points of the spleen (figure 1). measurement. Longitudinal size measurement was per-

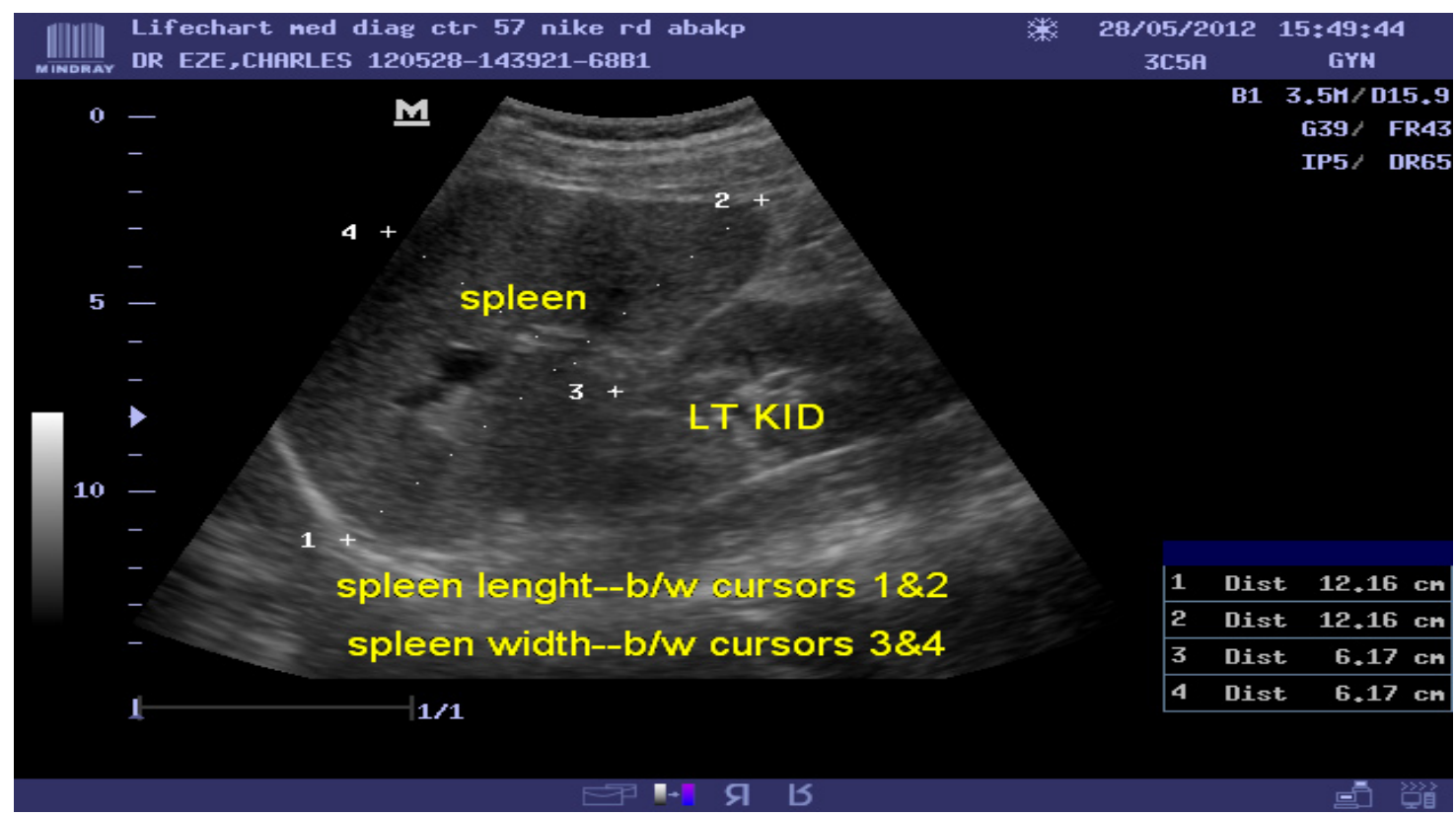

Figure 1. Sonogram of the length of the spleen measured between the most superomedial and the most inferolateral margin of the spleen.

Left kidney longitudinal size measurement (bipolar) was hilum with the subjects in the supine or slightly right obtained in the coronal plane passing through the renal lateral decubitus position (figure 2).

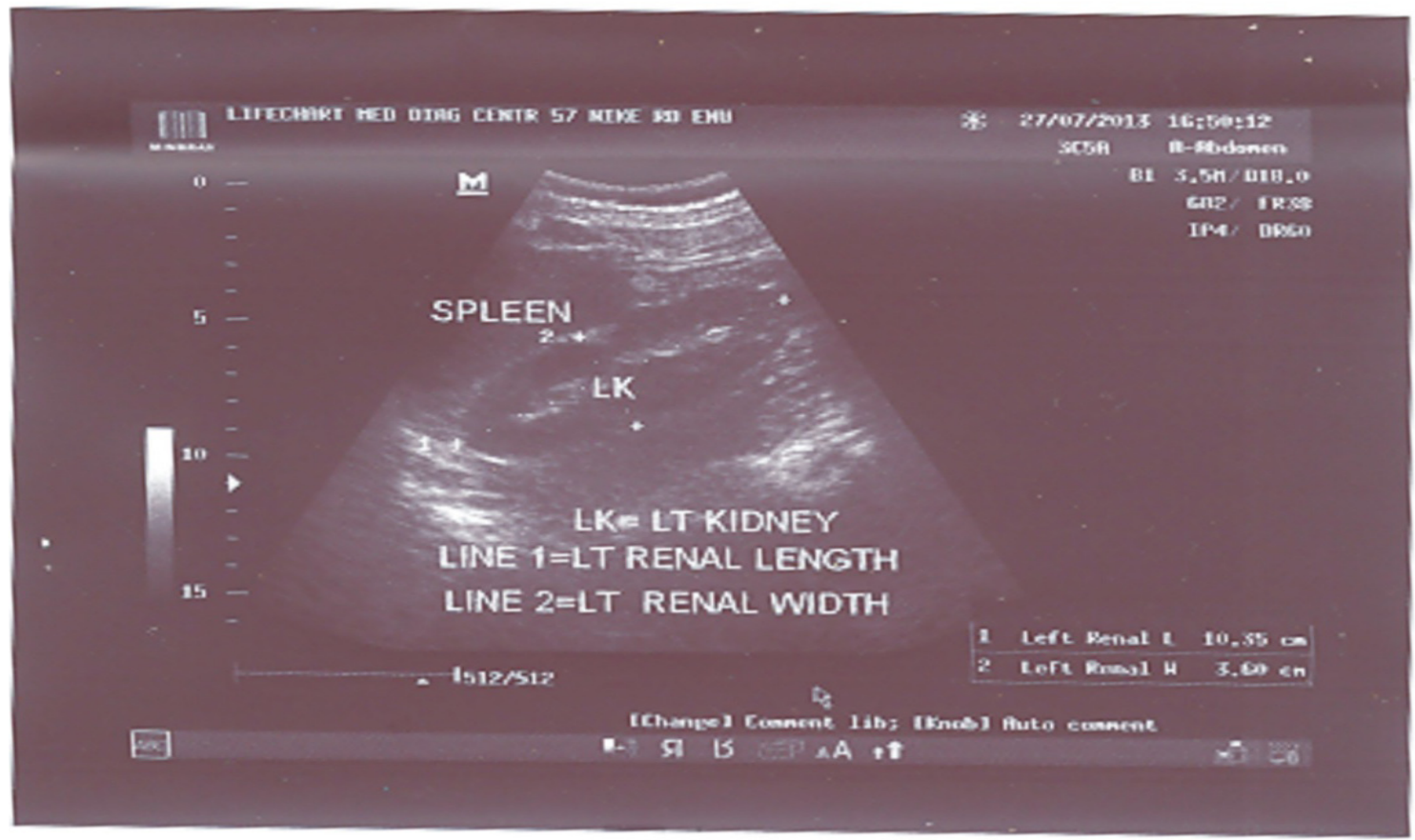

Figure 2. Sonogram of bipolar measurement of left kidney length. 
These techniques were used because of superior advantage of obtaining easily the longest dimension of the spleen and left kidney and reproducibility of measurements ${ }^{11-14}$. The choice of probe depends on the age and physique of the subjects.

A subgroup of twenty participants underwent two ultrasound scans of the organs done two days apart by two different sonographers to determine intra- and inter rater reliability of spleen size measurements (pilot study). The sonographers have 14 years of experience in abdominal sonography. One of these sonographers did all the scanning for the main study.

Spleen and left kidney lengths were measured three times, and the mean values were recorded. The spleen and left kidney studied had normal position, shape and echotexture prior to measurements. The measurement of organ dimensions was made during deep inspiration.

Statistical Analysis: Difference of continuous variables between two independent groups was assessed with the Student's t-test while more than two groups were assessed with analysis of variance (ANOVA). Intra class correlation coefficients (ICCS) were calculated to assess inter- and intra rater reliability for ultrasound measurement of the spleen, using SPSS statistical package version 10.14 (SPSS Chicago, Illinois, USA). Statistical significance was considered at $p<0.05$. Descriptive statistical methods were used when appropriate.

\section{Results.}

Table 1 shows high intra- and inter rater reliability in the measurement of spleen and left kidney lengths. The intra- and inter variability coefficients in the measurement of spleen length are 0.88 and $\mathbf{0 . 8 0}$ respectively while that of left kidney length are 0.89 and 0.84 respectively. The mean values of the spleen and left kidney lengths in the entire population studied are $91.03 \pm 10.72 \mathrm{~mm}$ and $81.61 \pm 8.32 \mathrm{~mm}$ respectively. The anthropometric variables include: age $=11.66 \pm 3.37$ years; height $=140.24 \pm 17.93 \mathrm{~cm}$; weight $=34.88 \pm 12.23 \mathrm{~kg} ; \mathrm{BSA}$ $=1.16 \pm 0.28 \mathrm{~cm}^{2}$ and $\mathrm{BMI}=17.10 \pm 2.06 \mathrm{~kg} / \mathrm{m}^{2}$.

Table 2: Spleen to Left Kidney Ratio According to Age in the Normal Subjects.

Table 1: Intra- and Inter Rater Reliability of Sonographic Measurement of Spleen and Left Kidney Lengths.

$\begin{array}{ll}\text { Observer } & \text { Intra- and Inter rater reliability } \\ \text { Intraobserver, } & \text { Intra rater reliability } \\ \text { Sonographer } 1 & \text { Spleen Length }=\operatorname{ICC}(2,1)=0.86 \\ & \text { Left kidney Length }=\operatorname{ICC}(2,1)=0.90 \\ & \text { Intra rater reliability } \\ \text { Intraobserver, } & \text { Spleen Length }=\operatorname{ICC}(2,1)=0.90 \\ \text { Sonographer 2 } & \text { Left Kidney Length }=\operatorname{ICC}(2,1)=0.88 \\ & \\ \text { Interobserver, } & \text { Inter rater reliability } \\ \text { Both Sonographers } & \text { Spleen Length }=\operatorname{ICC}(2,1)=0.80 \\ & \text { Left Kidney Length }=\operatorname{ICC}(2,1)=0.84\end{array}$

ICC $=$ Intra class correlation coefficient; ICC $(2,1)=$ Intra class correlation coefficient between the first and second measurements obtained by each sonographer (intra observer) and between the first measurements obtained by both sonographers (inter observer). 
The spleen to left kidney ratio (SLKR) according to age, constant around 1.13 with a range of $1.0-1.3$. Using height, weight, BMI and BSA in the studied subjects are 2 standard deviations (SD) above the mean as a guide, shown in tables 2, 3, 4, 5 and 6 respectively. The ratio is the upper limit of normal for the spleen to left kidney ratio is 1.3 .

Table 2: Spleen to Left Kidney Ratio According to Age in the Normal Subjects.

\begin{tabular}{lllllll}
\hline S/N & Age(years) & N(frequency) & Minimum & Maximum & Mean & SD \\
\hline 1 & 6 & 74 & 1.0 & 1.2 & 1.12 & 0.05 \\
2 & 7 & 65 & 1.0 & 1.3 & 1.12 & 0.07 \\
3 & 8 & 72 & 1.0 & 1.3 & 1.13 & 0.05 \\
4 & 9 & 65 & 1.0 & 1.3 & 1.13 & 0.06 \\
5 & 10 & 94 & 1.0 & 1.3 & 1.13 & 0.06 \\
6 & 11 & 1.0 & 1.2 & 1.11 & 0.05 \\
7 & 12 & 75 & 1.0 & 1.3 & 1.11 & 0.06 \\
8 & 13 & 72 & 1.0 & 1.3 & 1.10 & 0.08 \\
9 & 14 & 107 & 1.0 & 1.3 & 1.13 & 0.08 \\
10 & 15 & 87 & 1.0 & 1.3 & 1.13 & 0.07 \\
11 & 16 & 70 & 1.0 & 1.3 & 1.16 & 0.08 \\
12 & 17 & 67 & 1.1 & 1.3 & 1.17 & 0.06 \\
\hline
\end{tabular}

Table 3: Spleen to Left Kidney Ratio According to Height in the Normal Subjects.

\begin{tabular}{lllllll}
\hline $\mathrm{S} / \mathrm{N}$ & Height $(\mathrm{cm})$ & $\mathrm{N}$ (frequency) & Minimum & Maximum & Mean & $\mathrm{SD}$ \\
\hline 1 & $102-112$ & 44 & 1.0 & 1.3 & 1.13 & 0.06 \\
2 & $113-123$ & 148 & 1.0 & 1.3 & 1.13 & 0.06 \\
3 & $124-134$ & 192 & 1.0 & 1.3 & 1.12 & 0.05 \\
4 & $135-145$ & 201 & 1.0 & 1.3 & 1.13 & 0.06 \\
5 & $146-156$ & 142 & 1.0 & 1.3 & 1.11 & 0.07 \\
6 & $157-167$ & 135 & 1.0 & 1.3 & 1.15 & 0.08 \\
7 & $168-178$ & 85 & 1.1 & 1.3 & 1.16 & 0.07 \\
\hline & Total & 947 & 1.0 & 1.3 & 1.13 & 0.06
\end{tabular}


Table 4: Spleen to Left Kidney Ratio According to Weight in the Normal Subjects.

\begin{tabular}{|c|c|c|c|c|c|c|}
\hline $\mathrm{S} / \mathrm{N}$ & weight(kg) & $\mathrm{N}$ (frequency) & Minimum & Maximum & Mean & SD \\
\hline 1 & $16-21$ & 136 & 1.0 & 1.3 & 1.14 & 0.06 \\
\hline 2 & $22-27$ & 166 & 1.0 & 1.3 & 1.11 & 0.06 \\
\hline 3 & $28-33$ & 242 & 1.0 & 1.3 & 1.13 & 0.06 \\
\hline 4 & $34-39$ & 82 & 1.0 & 1.3 & 1.09 & 0.06 \\
\hline 5 & $40-45$ & 114 & 1.0 & 1.3 & 1.12 & 0.08 \\
\hline 6 & $46-51$ & 68 & 1.0 & 1.3 & 1.14 & 0.07 \\
\hline 7 & $52-57$ & 93 & 1.0 & 1.3 & 1.15 & 0.07 \\
\hline 8 & $58-63$ & 39 & 1.1 & 1.3 & 1.21 & 0.07 \\
\hline 9 & 64-69 & 7 & 1.1 & 1.2 & 1.19 & 0.04 \\
\hline \multicolumn{2}{|c|}{ Total } & 947 & 1.0 & 1.3 & 1.14 & 0.06 \\
\hline
\end{tabular}

Table 5: Spleen to Left Kidney Ratio According to BMI in the Normal Subjects.

\begin{tabular}{|c|c|c|c|c|c|c|}
\hline $\mathrm{S} / \mathrm{N}$ & $\operatorname{BMI}\left(\mathrm{kg} / \mathrm{m}^{2}\right)$ & $\mathrm{N}$ (frequency) & Minimum & Maximum & Mean & $\mathrm{SD}$ \\
\hline 1 & $13.0-14.9$ & 92 & 1.0 & 1.2 & 1.12 & 0.04 \\
\hline 2 & $15.0-16.9$ & 469 & 1.0 & 1.3 & 1.13 & 0.06 \\
\hline 3 & $17.0-18.9$ & 217 & 1.0 & 1.3 & 1.13 & 0.07 \\
\hline 4 & $19.0-20.9$ & 113 & 1.1 & 1.3 & 1.15 & 0.09 \\
\hline 5 & 21.0-22.9 & 40 & 1.1 & 1.3 & 1.15 & 0.06 \\
\hline 6 & $23.0-24.9$ & 15 & 1.1 & 1.3 & 1.19 & 0.08 \\
\hline 7 & $25.0-26.9$ & 1 & 1.1 & 1.1 & 1.10 & 0.00 \\
\hline \multicolumn{2}{|c|}{ Total } & 947 & 1.0 & 1.3 & 1.14 & 0.06 \\
\hline
\end{tabular}


Table 6: Spleen to Left Kidney Ratio According to BSA in the Normal Subjects.

\begin{tabular}{lllllll}
\hline S/N & BSA $\left(\mathrm{cm}^{2}\right)$ & N(frequency) & Minimum & Maximum & Mean & SD \\
\hline 1 & $0.6-0.7$ & 22 & 1.0 & 1.2 & 1.11 & 0.04 \\
2 & $0.8-0.9$ & 212 & 1.0 & 1.3 & 1.13 & 0.06 \\
3 & $1.0-1.1$ & 296 & 1.0 & 1.3 & 1.13 & 0.06 \\
4 & $1.2-1.3$ & 159 & 1.0 & 1.3 & 1.10 & 0.07 \\
5 & $1.4-1.5$ & 143 & 1.0 & 1.3 & 1.13 & 0.07 \\
6 & $1.6-1.7$ & 108 & 1.0 & 1.3 & 1.17 & 0.07 \\
7 & $1.8-1.9$ & 7 & 1.1 & 1.2 & 1.19 & 0.04 \\
\hline & Total & 947 & 1.0 & 1.3 & 1.14 & 0.06
\end{tabular}

\section{Discussion.}

Measurement of spleen and left kidney lengths were reliable within and between sonographers as shown by high intra- and inter rater reliability in this study. These findings support the historical assessment of visceral organ size based on longitudinal length measurement. The scan and measurements in this study were performed by a certified and an experienced sonographer to reduce inter-observer errors. A previous study has shown that experience has an influence on measurement accuracy during ultrasound scanning ${ }^{15}$. To minimize intra- observer errors, organ dimensions were measured three times and the mean values were recorded.

In this study, school age children ranging from $6-17$ years were studied. This age range of $6-17$ years of the studied subjects is in keeping with school-age children in Nigeria ${ }^{16}$. Nigerian children have specific issues relating to spleen size because of malaria, typhoid fever, malnutrition and environmental issues which increase spleen size compared to the rest of the developed world. To the best of the authors' knowledge, literatures reviewed showed that this study covers the largest series of paediatric spleen to left kidney ratio by sonography involving the age range of 6-17 years in any Nigerian population.

Present study has shown that there were no significant differences in the measured spleen and left kidney lengths with respect to sex $(p>0.05)$. This finding is similar to the findings of other previous authors ${ }^{5,6,17,18}$. Therefore, sex certainly is not a determining factor for spleen and left kidney lengths in school-age children in this population. The absence of gender difference in the dimension of both ultrasound of left kidney and spleen suggests a non - involvement of sex hormones in the development of these organs until the age of 18 years.

Some investigators have sought to establish an internal reference standard against which the spleen size can be calibrated. The most common of such strategy is to compare the length of the spleen to the length of the left kidney. Loftus and Metreweli ${ }^{5}$ as well as $\mathrm{Al}$ Imam et $\mathrm{al}^{6}$ found that the spleen to left kidney ratio was constant for all age groups with a mean value of 1 and proposed a ratio of 1.25 as the upper limit of normal in a paediatric population. Because of racial differences in spleen size, knowledge of the spleen to left kidney ratio in the population being examined is a prerequisite ${ }^{8}$.

In the present study the spleen to left kidney ratio is strikingly constant at around 1.13 for all ages as well as other biometric parameters such as height, weight, BMI and BSA studied. Using 2 standard deviations above the mean as a guide, the upper limit of normal for the spleen to left kidney ratio is 1.3. Thus splenomegaly should be suspected in this school age children population if the spleen is more than 1.3 times longer than the adjacent left kidney in the absence of renal disease. In a similar study in adult population, spleen length was correlated with left kidney length in women, but not in men $^{7}$; they found the spleen to left kidney ratio to be an unreliable index for spleen size in adults and proposed the use of Look-up tables as references for daily use in busy practice settings. 
The implication from our study for the Nigerian ultrasound community is obvious because of possible variations in the anthropometric parameters of various populations, races and regions. It is important for Nigerians to have their own population specific values of the spleen to left kidney ratio in the studied age group as Americans and Europeans' population data cannot be used as universal patterns. Our results could be extrapolated to the wider international community where there is need for each country, especially tropical regions where malaria and typhoid fever are endemic, to establish their own population specific ratios of the spleen to left kidney size in school age children because of possible variations in this ratios in different ethnic origins or races.

\section{Limitations}

The limitations of this study include the fact that it was done in the Southeast geopolitical region of $\mathrm{Ni}$ geria which is inhabited by people of Igbo ethnic background. A multicentre study in other regions of the country might improve the precision of the estimates and also the generalizability of the data. Furthermore, the socio economic status of the children studied was not recorded. It is hoped that further studies will address these limitations.

\section{Recommendations}

The spleen to left kidney ratio can be used to exclude non palpable splenic enlargement objectively among school age children.

The spleen to left kidney ratio is strikingly constant around 1.13 with a range of $1-3$ with respect to age and somatometric parameters among school age children.

\section{Conclusion}

Ultrasound can be used to diagnose mild splenomegaly if the spleen is about 1.3 times longer than the adjacent left kidney in the absence of renal disease among school age children in the studied population.

\section{Acknowledgement.}

Many thanks to the director, medical and paramedical staff of university of Nigeria, Medical centre, Nsukka for providing the enabling support for the study.

\section{Conflict of interest}

None declared.

\section{References}

1. Federal ministry of Health (FMOH) Nigeria. Demographic and Health Survey. 2003; 10: 1-8.

2. Camitta BM. Splenomegaly. In: Kliegman RM, Behrman RE, Jenson HB, Staton BF. Eds. Nelson Textbook of Pediatrics. $18^{\text {th }}$ ed. Philadelphia, Pa: Saunders; 2007. p.2091.

3. Tamayo SG, Richman LS, Mathews WC et al. Examiner dependence on physical diagnostic tests for the detection of splenomegaly: a prospective study with multiple observers. Journal of General Internal Medicine 1993; 8: 69-75.

4. Megremis SD, Vlachonikolis IG, Tsilimigaki AM. Spleen length in childhood with US: normal values based on age, sex, and somatometric parameters. Radiology 2004; 231:129-134.

5. Loftus WK, Metereweli C. Ultrasound assessment of mild splenomegaly: spleen/kidney ratio. Paediatric Radiology 1998; 28:98-100.

6. Al-Imam O, Suleiman A, Khuleifat S. Ultrasound assessment of normal splenic length and spleen-to-kidney ratio in children. East Mediterranian Health Journal. 2000; 6: 514-516.

7. Spielman AL, DeLong DM, Kliewer MA. Sonographic evaluation of spleen size in tall healthy athletes. American Journal of Roentgenology. 2005; 184: 45-9.

8. Hosey RG, Mattacola CG, Kriss V, Armsey T, Quarles DJ, Jagger J. Ultrasound assessment of spleen size in collegiate athletes. British Journal of Sports Medicine 2006; 40:251-254.

9. Mostelled RD. Simplified calculation of body surface area (letter). New England Journal of Medicine 1987; 317: 1098.

10. Norton K and Olds I (eds). Anthropometrica. A textbook of body measurement for sports and health course. Sydney: University of New South Wales Press. 1996; PP 25-73.

11. Sarac K, Kutlu R, Yakinci C, Durmaz Y, Baysal T, Ozgen U. Sonographic evaluation of liver and spleen size in school- age children. Turkish Journal of Medical Sciences 2000; 30:187-190.

12. Safak AA, Simsek E, Bahcebasi . Sonographic assessment of the normal limits and percentile curves of liver, spleen and kidney dimensions in healthy schoolaged children. Journal of Ultrasound Medicine 2005; 24(10): 1359-1364.

13. Megremis SD, Vlachonikolis IG, Tsilimigaki AM. Spleen length in childhood with US: normal values based on age, sex, and somatometric parameters. Radiology 2004; 231:129-134. 
14. Konus OL, Ozdemir A, Akkaya A, Erba G, Celik $\mathrm{H}$, Isik S. Normal liver, spleen and kidney dimension in neonates, infants and children: evaluation with sonography. American Journal of Roentgenology 1998; 171:16931698.

15. Roland GLD, Thomas D, Jan AD, Dominique VS, Ingrid W, Dirk T, et al. Ultrasound determination of chorionicity in twin pregnancy: accuracy and operator experience. Twin Research and Human Genetics 2001; 4: $223-226$.

16. Ogunfowora OB, Olanrewaju DM, Akenzua GI. A comparative study of academic achievement of children with sickle cell anemia and their healthy siblings. Journal of National Medical Association 2005; 97(3); 405-408.

17. Soyupak SK, Narli N, Yapicioglu H, Satar M, Sungur EH. Sonographic measurements of the liver, spleen and kidney dimensions in the healthy term and preterm newborns. European Journal of Radiology 2002; 43:73-78. 18. Achim OF, Vestemean IL. Ultrasound relation between the dimension of the spleen and left kidney in children. Acta Medica Transilvanica 2010; 2(4): 251 - 252. 